World Chemistry Leadership Meeting (WCLM)

In the WCLM forum, members of the National Adhering Organizations (NAO) have an opportunity to come together and discuss emerging issues. This year, the theme of WCLM was 'IUPAC's role in developing interdisciplinary/collaborative work in the chemistry community and beyond". The programming, led by Hemda Garelick and Chris Ober, was supported by the active participation of many IUPAC members, including Jan Apotheker, Valdimir Gubala and Pietro Tundo.

This year again, the WCLM activities were designed to engage with the Young Observers. In addition, the International Younger Chemists Network (IYCN) was also involved in bringing younger energy to many activities in IUPAC. The WCLM team will report separately.

\section{IUPAC Centenary}

In July 1919, chemists from France, Italy, Belgium, UK and USA met in Paris and founded IUPAC. There are plans to celebrate IUPAC centenary in 2019 and with this in mind, IUPAC100 Management Committee has been formed with Mary Garson and Laura McConnell as co-chairs. A number of events are being planned which includes periodic table competition, Green Chemistry
Summer School, proposals from young chemists, IUPAC100 World Chemistry Leadership Meetings etc. The 2019 anniversary represents an opportunity to celebrate the role and contributions of chemistry within society, today and into the future, and is not solely a celebration of the IUPAC birthday. National events to celebrate IUPAC100 are encouraged. (see more p.35)

\section{Closing Ceremony}

After one week of hectic activities, IUPAC $46^{\text {th }}$ World Chemistry Congress and $49^{\text {th }}$ General Assembly came to an end on 14 July. It was a grand success due to hard work by the Brazilian Chemical Society and IUPAC Secretariat.

At the closing ceremony, Professor Nicole Moreau, former IUPAC President, invited the audience to gather in Paris for IUPAC 2019 and on the occasion of IUPAC Centenary.

Dr Bipul Behari Saha, <drbsaha@rediffmail.com> is an Indian delegate, member of the IUPAC Committee on Chemistry and Industry (COCl). He is Director of R\&D at L R Research Laboratories, Nagarjuna Ageichem Limited, Hyderabad, India.

View the Photo Gallery at iupac2017.org

\title{
Un for Discussion
}

A forum for members and member organizations to share ideas and concerns.

Send your comments by e-mail to <edit.ci@iupac.org>.
From Young Observers to Young Actors: A Message to IUPAC from a few Young Observers

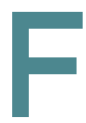

or many years, IUPAC has opened its doors to the younger chemists as observers to its activities, welcoming them in the midst of their General Assemblies. This is a unique opportunity for younger chemists to acquaint themselves with the work of the Divisions and Committees at an early stage and with limited commitment. In an article published in 2002, the Young Observers (YOs) program was characterized as "a way to seek innovative scientists" and "bring new expertise to IUPAC" [1]. Since 2013, the World Chemistry Leadership Meeting (WCLM) has invited all young observers to its symposium. In 2017, with a clever combination of "speed-networking" round tables, brainstorming and projects-crafting during the symposium, there is strong hope that a significant proportion of young observers will return as IUPAC active members during future meetings in Paris (2019) and Montréal (2021).

We were all very interested in participating in these activities, useful to newcomers, and we would like to thank IUPAC2017 organizing team as well as the symposia conveners for the excellent program that was put together to the mutual benefit of IUPAC members and younger chemists.

This being said, almost all division members we met expressed their concern about our generation not being involved enough with the Union. We often heard 
that there should be many more Young Observers: a challenging goal, not only because of limited funding from national societies and sponsors but also by lack of interest amongst early-stage career chemists who, busy in establishing themselves as independent and successful scientists, do not see their involvement with IUPAC as a way to achieve their objectives.

In addition to activities that already involve YOs, wouldn't there be a more operative way to engage and empower the youth? To reverse the trend and make IUPAC more attractive and open to our generation, we propose a recast of the role of the Youth in IUPAC, more in line with current trends and the efforts of similar organizations.

The Young Observers attending IUPAC General Assemblies are in fact selected for their productivity, creativity, skills, and potential. They are already contributing to solve some of the greatest challenges of our time: climate change, resources scarcity, and energetic transition. On top of the scientific questions raised by these challenges (e.g. sustainable development, green chemistry, renewable energy resources, and all technologies dealing with safety and healthcare), our generation will also-sooner rather than later-have to address the political and humanist ones: insuring that shared knowledge is not turned into weapons, and that politicians receive appropriate advice in society-defining decisions. In other words, fight the "fake news." In the long haul, collaboration of IUPAC with organizations such as the Organization for the Prohibition of Chemical Weapons (OPCW) seems especially relevant, and it will require the involvement of the younger generations [2,3]. Today, IUPAC leadership plays a critical role in these matters, but it should strengthen its endeavor to prepare its succession.

Undoubtedly, every newcomer has a lot to learn about IUPAC machinery. The same applies for members freshly elected in Divisions and Committees, yet they are not asked to observe but to get immediately involved in the activities of their groups. We minimize our ability to attract the best and bright young chemists to IUPAC if we keep treating them as observers. All the attendees to the General Assembly are active early career professionals, and some of them, under 45 (current age limit for YO), are already prolific and accomplished scientists, who should be treated as peers rather than mere observers.

We thus propose that the passive connotation of an "Observer" should be replaced by a more engaging one, not just in the naming. We believe that there simply is no time to lose in tackling our main global problems, especially since we are ready to contribute. Today, we propose to set together well-defined goals, such as

By 2018, a web presence for Younger Chemists within IUPAC is established via both website and social media.

By 2019, each division and committee has elected a member that will work with the YOs and International Younger Chemists Network as a liaison to both mentor but also hear new ideas from the younger chemists.

By 2021 each division has one member under the age of 45 .

We write this letter in a spirit of dialog and cooperation to build a stronger and more inclusive organization, not only as Young Observers, but also as peers willing to work together to create a better world through Chemistry. To that regard, we believe that the recent creation of the International Younger Chemists Network (IYCN) [4], here in São Paulo, is highly encouraging. We call on IUPAC to associate its young members to the centenary celebration (IUPAC100), not only as observers, but as participants and as co-leaders to some of the relevant events and symposia, such as WCLM.

São Paulo, 14 July 2017.

Disclaimer: The opinions expressed in this letter are these of the individuals who signed it. In no quality does this letter express officia positions of their affil tions.

Sophie Carenco (Paris, France - Researcher at CNRS), Laurean llies (Tokyo, Japan - Associate Professor at the University of Tokyo), Leonardo Scarabelli (Pavia, Italy - Post-doctoral fellow at the University of (alifornia, Los Angeles), Dean Tantillo (Davis California, USA - Professor at the University of California, Davis). Signatories were Young Observers at the $49^{\text {th }}$ General Assembly of IUPAC in São Paulo, Brazil.

\section{References}

1. E. P. Przybylowicz, Chem.Int, 24(1):7-9 (2002)

2. OPCW and IUPAC Take Partnership to New Level (1 Dec 2016); www.opcw.org/news/article/opcwand-international-union-of-pure-and-appliedchemistry-take-partnership-to-new-level/

3. https://iupac.org/iupac-opcw-take-partnershipnew-level/

4. C. E. Dunne and F. Gomollón-Bel, Chem. Int., 39(2):4-6 (2017) 